\title{
La discusión acerca del argumento anselmiano: algunas reflexiones en torno a la experiencia sentida
}

\section{The discussion about the anselmian argument: some reflections around the felt experience}

\author{
Mauricio Otaíza Morales ${ }^{1}$ \\ Instituto de Filosofía, Pontificia Universidad Católica de Valparaíso, Chile
}

(Recepción: Agosto 2007 - Aceptación: Febrero 2008)

\begin{abstract}
Resumen
La discusión sobre el argumento anselmiano se reedita inexplicablemente una y otra vez a lo largo de la historia y es una cuestión particularmente importante para la Filosofía de la Psicología. Si se considera la solidísima línea de argumentación iniciada por Gaunilón y continuada por Kant parece muy extraña la vigencia del problema. Sin embargo, hay algo que nos parece todavía más extraño: la pueril obviedad de las objeciones a San Anselmo. Creemos que nos encontramos ante uno de varios célebres diálogos de sordos fundados en una todavía insuficiente comprensión de la experiencia sentida activada por el símbolo maius.

Palabras clave: San Anselmo, experiencia, maius.
\end{abstract}

\begin{abstract}
The discussion on the anselmian argument is reedited inexplicably throughout history and it is a particularly important question for the Philosophy of Psychology. If we think in the very solid argumentation initiated by Gaunilón and continued by Kant the use of this problem seems very strange. Nevertheless, there is something still seems to us more stranger: the pueril obviety of the objections to Saint Anselm. Let us think that we still were before one of several famous dialogues of deaf people founded on an insufficient understanding of the felt experience activated by the symbol maius.
\end{abstract}

Key words: Saint Anselm, experience, maius.

La Profesora Laura Palma Villareal observaba algo muy curioso:

Muy larga y variada en el curso de la historia de la filosofía es, como sabemos, la trayectoria del argumento que, desde Kant en adelante, se conoció bajo la denominación de 'argumento ontológico'. Desde su invención, éste aparece y reaparece porfiadamente con renovadas energías a lo largo de los siglos, a pesar de las severas y acuciosas críticas una y otra vez recibidas. (Palma 15).

San Anselmo exponía la demostración de la existencia de Dios con la siguiente fórmula: Deus enim est id quo maius cognitari non potest ${ }^{2}$ (pues Dios es algo de lo cual no se podría pensar nada mayor). Analicemos el siguiente ejemplo. Un pintor se queja porque no puede cobrar su paga entregando la mera idea de un retrato a su cliente pues éste demanda la obra en concreto y no algo a lo cual le falta existencia. En este caso, el cliente considera que la mera idea de retrato es minus respecto del retrato real, pues tal idea está privada de la existencia requerida ${ }^{3}$. Parece discutible, sin

1 Correspondencia a: Mauricio Otaíza Morales. Dirección: Avenida El Bosque, 1290, Viña del Mar, Chile. Tel. (56-32) 2274391 (56-32) 2274333 E-mail: mauricio.otaiza@ucv.cl

2 San Anselmo. Proslogion 3-4, capitulum IV. Opera Omnia, Alemania: Friedrich, 1968.

3 Cf. Ibid., capitulum II. Nam cum pictor praecogitat quae facturus est, habet quidem in intellectu, sed nondum intelligit esse quod nondum fecit. Cum vero iam pinxit, et habet in intellectu et intelligit esse quod iam fecit. Convicintur ergo etiam insipiens esse vel in intellectu aliquid quo nihil maius cogitari potest, quia hoc cum audit. Intelligit, et quidquid intelligitur in intellectu est. Et certe id quo maius cogitari nequit, non potest esse in solo intellectu. Si enim vel in solo intellectu est, potest cogitari esse et in re, quod maius est. Si ergo id quo maius cogitari non potest, est in solo intellectu: id ipsum quo 
embargo, que necesariamente la existencia añada perfección a la idea de algo. En efecto, tal vez se dé el caso de que al cliente le convenga conformarse con un retrato imaginario antes que pagar por un mamarracho y, es más, es seguro que en este contexto le conviene devolver la mano pagando con dinero imaginario.

Pues bien, igualmente parece discutible que si se ha de tener la idea de un Dios como algo sumamente perfecto se lo tenga que pensar como no estando privado de existencia. El monje Gaunilon denunció que el argumento anselmiano constituía un salto de lo lógico a lo ontológico. Por el argumento de Anselmo, sugería el monje, no se puede concluir la existencia de Dios, así como tampoco se puede concluir la existencia de una isla paradisíaca, por muy paradisíaca que la pensemos y por mucho que convenga que esta isla exista.

San Anselmo, por su parte, respondió que la idea de Dios y la idea de tal isla no son comparables, porque mientras la idea de Dios es la idea de un ser inmaterial y necesariamente existente, la idea de tal isla es la idea de un cuerpo material y contingente, y por mucho que tal isla sea concebida de una belleza extraordinaria, etc. Es decir, señalaba Anselmo, no habría nada en la idea de tal isla que obligara a pensarla como necesariamente existente.

Gaunilón, por supuesto, no quedó conforme con la respuesta, ni tampoco muchos filosófos después de él. Immanuel Kant, por ejemplo, aprovechó de objetar a San Anselmo mientras rebatía las demostraciones cartesianas de la Tercera Meditación ${ }^{4}$.

Kant sostuvo que por este tipo de argumentos -que llamó “ontológicos”-sólo se podría demostrar la necesidad de la idea de un Dios existente, pero no la necesidad de la existencia de un Dios 5 . La objeción kantiana considera que el argumento ontológico implica un problema categorial, un problema que trata, precisamente, sobre lo que puede ser pensado (cogitari potest), y nada más. La existencia de Dios queda, entonces, relegada al campo del noúmeno y es, por tanto, una problemática "X".

Si hemos de seguir a Gaunilón y a Kant, debemos suponer que Anselmo, o bien no tenía el más mínimo sentido común o bien no entendía prácticamente nada de lógica elemental. Curiosos supuestos para comprender a un filósofo educado por los benedictinos y que llegó a ser arzobispo de Canterbury. Pues bien, el calificativo empleado por Kant para referirse a este intento "ontológico" -“ganz leicht” (completamente fácil)- no deja de ser sugerente.

Retomemos el asunto. San Anselmo sostiene que quien diga que entiende lo que significa este término "Dios" debe, o bien admitir que por tal término refiere un Dios que existe, o bien debe retractarse y admitir que no entiende realmente lo que este término "Dios" significa.

Gaunilón debate con Anselmo, lo cual significa hacer explícito algo que damos por obvio, a saber: mucho, pero realmente muchísimo antes que dos personas discutiendo sobre una misma idea de Dios, nos encontramos frente a dos personas con dos ideas cuyos contenidos dicen relación con estos símbolos: Deus y maius.

Se dirá -con algo de razón- que del mismo hecho que Anselmo y Gaunilón (y Kant) discutan se sigue que existe alguna razón análoga que alcanza a salvar las diferencias mínimas de comprensión.

maius cogitari non potest, est quo maius cogitari potest. Sed certe hoc esse non potest. Existit ergo procul dubio aliquid quo maius cogitari non valet, et in intellectu et in re.

4 Cf. Descartes, René. Méditations Métaphysiques. Paris: Libraire Philosophique J. Vrin, 1966, p. 46-47.

5 "En todos los tiempos se ha hablado de un ser absolutamente necesario [absolut notwendigen], pero ha habido menos preocupación por comprender si es posible -y cómo lo es- concebir simplemente una cosa semejante, que por demostrar su existencia. Es, por supuesto, muy fácil [ganz leicht] dar una definición nominal [Namenerklärung] de este concepto diciendo que es algo cuyo no-ser es imposible. Pero con ello no sabemos más que antes acerca de las condiciones que hacen necesario considerar el no-ser de una cosa como absolutamente impensable y que son precisamente lo que pretendemos conocer, es decir, si mediante este concepto pensamos algo o no pensamos nada. En efecto, el hecho de rechazar por medio de la palabra 'incondicionado' todas las condiciones que son siempre indispensables al entendimiento para considerar algo como necesario, dista mucho de hacernos comprender si pensamos algo o quizás nada en absoluto a través del concepto de un ser incondicionadamente perfecto". Kant, Immanuel. Crítica de la razón pura, de la imposibilidad de una prueba ontológica de la existencia de Dios, México: Alfaguara. 2003, p. 500. 
No lo creemos. Antes, habría que preguntarse si la comprensión de estos términos: id quo maius cognitari non potest, y especialmente Deus y maius, se deja compartir con suficiencia mediante una analogía. Y decimos "con suficiencia" pues precisamente parece haber casos en los cuales una sobrevaloración del poder de las analogías podría ocultar la ayuda que ellas son capaces de prestarnos. En efecto, en lo personal se me dificulta comprender los dolores de parto y afirmar que la sed es hambre pero de agua y que el hambre es sed pero de comida y, en consecuencia, tiendo a creer que existe al menos un nivel en el cual las comprensiones de las ideas de Deus y maius de Anselmo de Gaunilón y de Kant podrían ser, por lo pronto y según el tenor de la discusión exhibida, mutuamente irreductibles.

Gaunilón y Kant, entre otros, han objetado con claridad y energía a San Anselmo, pero lo han hecho sobre un supuesto que nos parece trivial: un presunto salto de lo lógico a lo ontológico.

La cuestión pendiente estriba en saber si los objetores comprenden el Deus y el maius en los términos utilizados por Anselmo. Si no es el caso, se explicaría en parte la vigencia del problema. Pero surge entonces el desafío de ahondar en lo que estos términos, Deus y maius -y, sobre todo, maius-, podrían significar.

Se exige ahora atención al campo desde donde arranca toda posibilidad de analogía pero que, como se ha sugerido, también ha ofrecido tradicionalmente escenarios problemáticos: la experiencia humana, es decir, a fin de cuentas, desde donde emanan los significados.

Pero entonces se sitúa la discusión en un ámbito desprestigiado en los debates filosóficos: la experiencia vivida de cada cual. En efecto, llegados a este punto de la problemática fácilmente se escucha el calificativo: "psicologismo", lo que nos parece un prejuicio inaceptable.

La comprensión profunda arranca de la experiencia vivida, y hacer de la experiencia vivida y de lo sentido una cuestión de deseo y de mera voluntad constituye una opinión reduccionista y superficial, pues si fuera cierto que la experiencia vivida es producto del deseo y la voluntad todos seríamos más felices y durante más tiempo.

Este prejuicio sobreviene, creemos, de una consideración secundaria de la experiencia, a saber, su estatuto epistémico en comparación con la ciencia en cuanto apodíctica. Pero saber que algo es verdad y poderlo demostrar, no siempre son sinónimos. Sin embargo, se nos dirá con algo de razón, las experiencias de San Anselmo, de Gaunilón y de Kant se han perdido para siempre. Pero esto parece ser sólo parcialmente cierto. La perenne vigencia del problema demuestra que algo comparece en las experiencias que hace que posteriormente cada cual se sienta extrañamente mejor interpretado, por ejemplo, por autores ya desaparecidos.

Hemos querido ilustrar el estado todavía pendiente de esta cuestión de la filosofía de la psicología y sugerir cierto escenario de relectura. Creemos que hoy existen investigaciones capaces de arrojar luces sobre estas históricas paradojas de la comprensión humana. Recordemos, por ejemplo, el fuerte trabajo fenomenológico desarrollado por el filósofo y psicólogo norteamericano Eugen Gendlin.

\section{Referencias}

Palma Villareal, L. Traducción y estudio de la obra Acerca del Ser de Louis Lavelle. Valparaíso: Ediciones Universitarias de Valparaíso, 1994.

San Anselmo. Proslogion 3-4, capitulum IV. Opera Omnia, Alemania: Friedrich, 1968.

Descartes, René. Méditations Métaphysiques. París: Libraire Philosophique J. Vrin, 1966.

Kant, Immanuel. Crítica de la razón pura, de la imposibilidad de una prueba ontológica de la existencia de Dios, México: Alfaguara, 2003. 